\title{
THE ROLE OF THE UNIVERSITY IN SOCIETY:
}

EXCEPTIONAL PUBLIC INTELLECTUALS OR ENGAGED INDTERDISCIPLINARY NEIGHBORS?

Scott Tate

Doctoral Candidate, ASPECT Program, Virginia Tech

atate1@vt.edu

Joseph Pitt is a faculty member in Virginia Tech's philosophy department. He has written on dangers facing the University. In doing so, he joins a significant body of scholarship on that topic, including John Henry Newman in the 1850's, Clark Kerr in the 1960's, and Jaroslav Pelikan in the 1990's. Pitt identifies four specific 'dangers' that imperil the American Research University. He describes the fourth danger as a "lack of faculty engagement in the public realm" $(2008,1) .{ }^{47}$ In response to this danger, he urges faculty to rise to the role of public intellectuals.

In this essay, I question both the spirit and the substance of Pitt's recommendations and argue that a better way to think about the role of the University's faculty, staff, and students in society is as 'engaged interdisciplinary neighbors'.

First, I critique the spirit of Pitt's recommendations. His essay contains a troubling theme of faculty exceptionalism. Pitt, for example, names students and faculty as the two essential components for a university $(2008,4)$. Faculty members are the sources and producers of knowledge, the guardians of our cultural heritage. Students are relegated to a passive role, as recipients of knowledge from the faculty, the caretakers of knowledge. The threats to the university, for Pitt, are mostly threats to faculty. He cites peripatetic administrators arriving with agendas and wielding their powers with little regard for institutional culture or consequences. Pitt attributes this disregard to a desire to move on to more prominent posts at other institutions.

Pitt reserves the work of institution-building for faculty and academic administrators. Pitt separates administration into academic and non-academic 
groupings. By academic administration, he refers to, "the likes of department chairs, deans, provosts, and maybe even presidents. They are responsible for ensuring the success of the threefold mission of preserving, creating, and transmitting knowledge." $(2008,11)$

By non-academic administration, Pitt refers to "registrars, comptrollers, vice presidents for facilities, vice presidents for finance, etc. These folks are responsible for keeping the books, making sure the buildings don't fall down, and maintaining records. They are essential support personnel."(2008, 11) Not only does Pitt relegate a very large contingent to the supporting cast, albeit an essential one, he warns against heeding these lesser elements:

Things go wrong, however, when the demands of the support staff takes precedence over the academic job. When, for example, the registrar's perceived need to process grades quickly results in a deadline for faculty to turn in final grades that does not give faculty ample time to grade final exams carefully and to compute final grades fairly.... When the support staff is allowed to arrange things for their convenience rather than in terms of academic importance, the students lose. And with respect to nonacademic administrators, that is all I want to say $(2008,11)$.

The undercurrent of faculty exceptionalism permeates Pitt's essay. He places faculty on quite a pedestal, as guardians of our cultural heritage. Pitt calls on faculty to be cultural guardians, knowledge producers, institution builders, and public intellectuals. This is problematic on a number of levels.

The modern American Research University is a place of increasing permeability and fluidity. Faculty, who Pitt lauds as guardians of knowledge, may not actually teach, or may only teach one or two courses per semester. So-called support personnel increasingly teach and engage in knowledge creation. Students, even undergraduates, are also often co-researchers, producers of knowledge. Graduate students are also 
classroom instructors and researchers. Students, both graduate and undergraduate, contribute to institution building and to the moral, spiritual, physical, intellectual, and emotional development of fellow students in a number of ways: through fraternities, clubs, sports teams, service organizations, and more. These activities serve multiple functions and provide spaces for sustained conversation about ideas as well as for experiential learning. Yet, Pitt describes no other significant role for students in the life of a university or in the life of the community beyond the university's walls.

Pitt paints an elitist picture of faculty as guardians and intellectuals, needed to rescue communities and carry the banner for culture and the "life of the mind" (2008, 33). I disagree. The public may be better served by some faculty remaining huddled in their offices. Not every academic should aspire to the role of public intellectual. Pitt assumes that faculty, who have subject area expertise, are natural public experts as well. This is false.

Second, I critique the substance of Pitt's recommendations. The fourth section of Pitt's essay, "The Public Intellectual" is my primary focus. Pitt describes a threat from public perceptions of the university, with concerns that universities are seen as either centers for job-training or as places of irrelevance. He traces these perceptions to cultural climate, to a public that fails to value the life of the mind, the world of ideas (see for example Pitt, 2008, 27). Pitt cites faculty as the primary culprits for failing to instill these kinds of values in students and for failing to engage publicly in order to defend these kinds of values.

In response, Pitt urges faculty to become public intellectuals. He asks for faculty to be advocates for the life of the mind, to write op-eds, to "make their points of view attractive enough to be considered in the public sphere" $(2008,33)$. Pitt offers a sentence or two on the need for university-community engagement, "A university cannot be a great university if it is not a vital part of the community's life and culture" (2008, 34). He also briefly praises the Extension mission of the land-grant university. However, he focuses the majority of his discussion on the role of faculty, imploring them to not to "sit behind our desks and ignore the world out there" $(2008,33)$. 
Beyond the spirit of exceptionalism, the substance of Pitt's solution is problematic. He fails to clearly state the meaning of "public intellectual". Richard Posner in his study of public intellectuals cites a lack of clarity around the term as well as a, "striking variance in the quality of public-intellectual work, coupled with a low average-quality" (2003, 2-3).

While faculty have an important public role to play, that role cannot simply be spreading around "expertise", like a gardener spreading so much manure. Posner urged caution in bemoaning the decline of the public intellectual because, "... with the enormous expansion in universities in the twentieth century, and in the leisure, credentials, and financial security that a university appointment offers to anyone who wants to embark on a career as a public intellectual, few would-be public intellectuals will fail to seek such appointments" $(2003,33)$. In studying public intellectuals, Posner found that the world of the public intellectual might be best described as a kind of super-specialized academic marketplace, similar to the one Pitt depicts in his discussion of peripatetic administrators.

I concur with Pitt that Universities should be concerned with engaging with the greater public. For Pitt, however, universities equal faculty and engagement equals public intellectuals. Moreover, Pitt fails to clearly describe what he means by public intellectuals, to provide workable solutions for how faculty might take on this role, or to provide a more comprehensive basis for university-community engagement. This is insufficient and leads me to my final point.

Third, I argue that the role of public intellectual is ill-suited to most faculty and that a better metaphor for faculty, staff, and students of a university is that of an engaged interdisciplinary neighbor. My first work in higher education was in the servicelearning and community outreach office of a small, private liberal arts college. Among other tasks that first year, I organized the annual Volunteer Fair, where representatives from community organizations came to campus, staffed tables, and met with potential student volunteers. The day was wrapping up. Paper plates and soda cans toppled from over-filled trash cans. I helped take down tables and carry boxes to cars. A 
middle school guidance counselor paused to chat, "Scott, I come to these every year. We get a few good volunteers and we're grateful. But, we have way over $50 \%$ of our students on free and reduced price lunch, our community is struggling, drugs are a big issue at our school. We need help."

She was not really complaining, just talking. Yet, afterward her words remained with me. Because of her words, we began working together and with other partners. Because of her words, we helped the school system apply for and receive a federal grant to help students in that middle school gain early awareness and readiness for higher education. Because of her words, we pursued another grant opportunity and our college was selected as one of only 13 institutions to take part in a massive three year national demonstration project titled, Engaging Campuses and Communities. The project involved faculty, staff, and students and had both curricular and co-curricular components. Because of her words, middle and high school students came to our campus for summer programming and travelled with college students to Atlanta, Washington DC, and Charleston, South Carolina. Because of her words, we started an on-campus after-school program, a leadership summit, a faculty service-learning initiative, a mentoring program, and a tutoring program.

I share this to illustrate that engagement is not just providing student volunteers and discrete resources. It is engaging with communities in the shared work of problemsolving. As Ernest Boyer wrote, “...the scholarship of engagement means connecting the rich resources of the university to our most pressing social, civic, and ethical problems, to our children, to our schools, to our teachers, and to our cities" (1996, p. 20).

This work is inherently interdisciplinary, in the most general and generous sense of that term. I am currently a doctoral student in an interdisciplinary doctoral program in social, political, ethical, and cultural thought. The program appealed to me, and still does, because of its emphasis on problem-solving. The program design recognizes that the big problems facing our communities, nations, and the world are all multi-faceted and require approaches that cross artificial lines that demarcate disciplinary niches. 
Such lines are barriers to both thought and progress. As Boyer put it, there is "... an urgent need to place discoveries in a larger context and create more interdisciplinary conversations" (1996, 15).

Beyond conversation, the cause of university-community engagement may also be served by urging faculty, staff, and students more to listen, to be receptive, to join a civic club, or to make dishes for a potluck. As Wendell Berry writes, "The real work of planet-saving will be small, humble, and humbling, and (insofar as it involves love), pleasing and rewarding. Its jobs will be too many to count, too many to report, too many to be publicly noticed or rewarded, too small to make anyone rich or famous." (1991, 19-27).

Perhaps this may be flirting with the seemingly ridiculous. I am not suggesting, however, that faculty, administrators, and students engage simply in menial or direct service. Instead, I suggest that a better way to engage in a community is to listen first, to build trust, to attempt to understand the conditions in specific places. Rather than ascending to the lofty pulpit of the public intellectual, we might try the dirty tasks of being helping neighbors. By "we", I refer to the larger university community of students, staff, administrators, faculty, alumni, and partners. I am not lauding a mythical, unified "local" community. Rather, I suggest that the "public" in "public intellectual" might be found in venues more modest and accessible than that of the opinion pages or the television news show.

For me, the university's role in community may be best articulated by John Dewey, who suggested that democracy is an on-going practice, a work that takes place in homes and schools and institutions, and that the "neighborly community" rests at the very heart of democracy (Dewey 1927, 213). To breach the divides between university and community means, I think, to see the shared work of democracy, to see that the problems of community are relevant for scholars and for the more broadly defined university community, and that there is a common work of public problemsolving to be undertaken. As Dewey put it, "...the idea of democracy is a wider and fuller idea than can be exemplified in the state, even in its best. To be realized, it must 
affect all modes of human association, the family, the school, industry, religion" (1954, 143).

Pitt writes that "...it is time to develop some courage and leave the sanctuary and meet the public in its own domain" (33). I concur. I would simply suggest that Pitt's "we" needs to be more inclusive of the entire University community and that his idea of public engagement should be grounded in a wide multitude of publics, many of which are easily accessible just past the campus boundaries. Universities might strive to join in building neighborly communities on multiple levels, and while a small number of faculty members may perhaps come to serve as public intellectuals, even more faculty, administrators, staff, and students might simply work to be good neighbors engaged in the inherently interdisciplinary problems of the places they inhabit.

\section{$\underline{\text { References }}$}

Berry, Wendell. (1993). Sex, Economy, Freedom, and Community. New York: Pantheon.

Boyer, Ernest. (1996). "The Scholarship of Engagement." Journal of Public Service and Outreach 1 (1): 11-20.

Dewey, John. (1954). The Public and Its Problems. Athens: Ohio University Press.

Kerr, Clark. (2001). The Uses of the University. Fifth Edition. Cambridge, MA: Harvard University Press.

Kirp, D. (2003). Shakespeare, Einstein, and the Bottom Line: The Marketing of Higher Education. Cambridge, MA: Harvard University Press.

Pitt, Joseph. (2008). "On the Idea of a University."

Posner, Richard. (2003). Public Intellectuals: A Study of Decline. Cambridge, MA: Harvard University Press. 